\title{
Atypical manometric abnormality of the lower esophageal sphincter: A procedure-related, stress-induced phenomenon?
}

\author{
BHUVANENDRAM INDRAKRISHNAN MD FRCPC, WILLIAM G PATERSON MD FRCPC
}

B INDRAKRISHNAN, WG PATERSON. Atypical manometric abnormality of the lower esophageal sphincter: A procedure-related, stress-induced phenomenon? Can J Gastroenterol 1995;9(6):349-351. Stress-induced esophageal contraction abnormalities have been well documented in the literature, but relatively little is known about stress-related lower esophageal sphincter (LES) dysfunction. Two patients are described in whom initial manometry studies revealed LES hypertension and impaired LES relaxation. Both patients were markedly anxious and agitated during the initial study. However, when the manometry was repeated with the patients in a calmer state, LES pressure and function were normal. These cases demonstrate the need to be aware of stress-related LES dysfunction. If this phenomenon is not identified in the appropriate settings, it could lead to significant errors in management.

Key Words: Esophageal manometry, Lower esophageal sphincter, Stress

Anomalie manométrique atypique du sphincter œsophagien inférieur : phénomène lié à l'intervention et induit par le stress

RÉSUMÉ : Les anomalies de la contraction de l'œsophage induites par le stress ont été bien documentées dans la littérature, mais on en sait relativement peu sur la dysfonction du sphincter œesophagien inférieur liée au stress. Deux patients sont décrits ici, chez lesquels des études manométriques initiales ont révélé une hypertension et un relâchement anormal du sphincter œesophagien inférieur. Les deux patients étaient nettement anxieux et agités lors de l'épreuve initiale. Toutefois, lorsque la manométrie a été refaite, alors que les patients étaient plus calmes, la pression et la fonction du sphincter œesophagien inférieur étaient normales. Ces cas démontrent la nécessité de se sensibiliser aux dysfonctions du sphincter œsophagien inférieur liées au stress. Si ce phénomène n'est pas identifié dans le contexte approprié, il pourrait entraîner de graves erreurs thérapeutiques.

Hotel Dieu Hospital, Gastrointestinal Diseases Research Unit, Queen's University, Kingston, Ontario

Correspondence and reprints: Dr WG Paterson, GI Division, Hotel Dieu Hospital, 166 Brock Street, Kingston, Ontario K7L 5G2. Telephone 613-544-3310 ext 2332, fax 613-544-3114

Received for publication October 3, 1994. Accepted March 7, 1995
ThREASING CLINICAL EXPERIENCE and experimental evidence suggest that psychological stressors can produce esophageal motility abnormalities (1). Psychologically stressful interviews may produce simultaneous and repetitive contractions (2), and loud noises or difficult mental tasks performed during manometry have been shown to increase the contraction amplitude and produce simultaneous contractions in the distal esophagus of normal subjects (3-5). Furthermore, a recent study demonstrated abnormal lower esophageal sphincter (LES) relaxation in healthy volunteers during experimental stress (6). Patients undergoing the stress of alcohol withdrawal have been observed to have hypertensive distal esophageal contractions and elevated LES pressures, which returned to normal after one month of abstinence (7). In one study, stress-induced abnormal motility was observed in healthy control subjects but the response was exaggerated in those with motility disorders, particularly nutcracker esophagus (8).

In the current report the authors describe two patients with symptoms suggestive of esophageal dysmotility in whom initial manometric studies showed hypertensive LES pressures and impaired LES relaxation. Both patients 


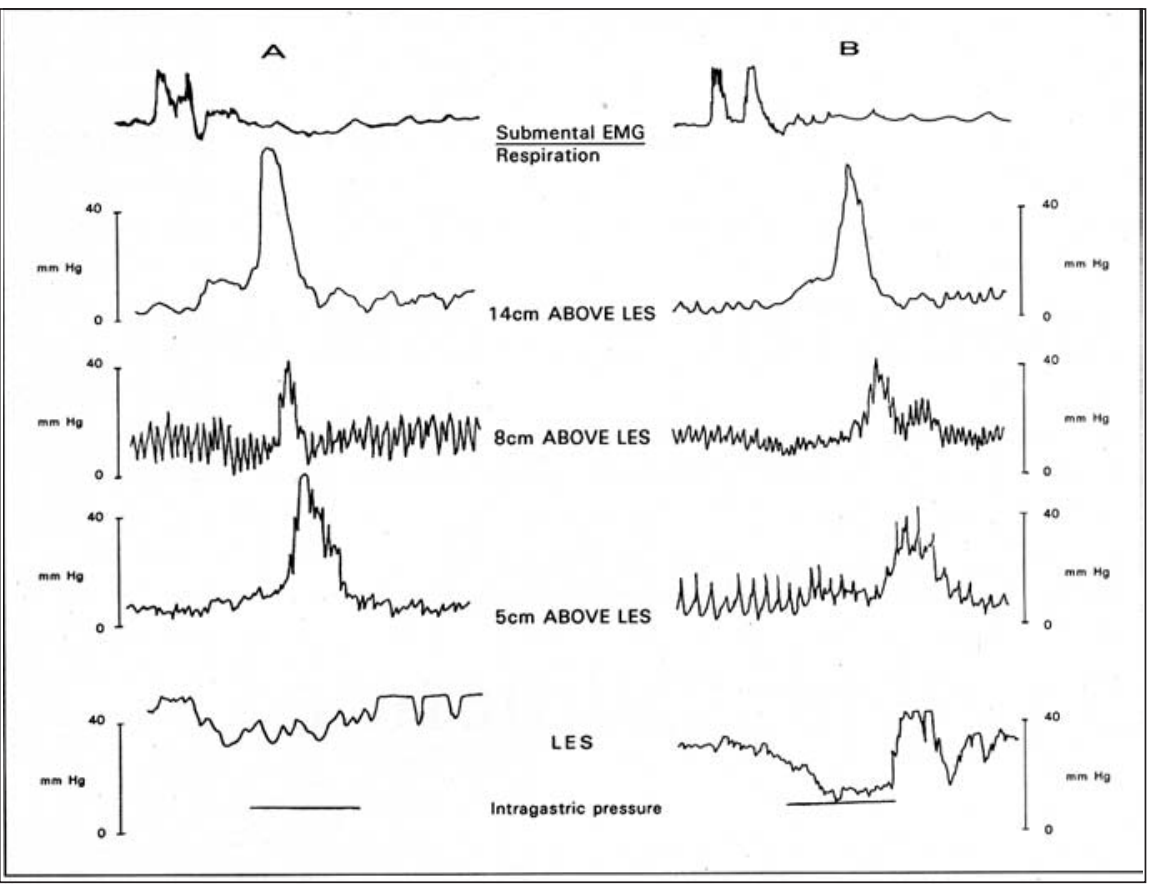

Figure 1) Initial manometric tracing from case 1 (A) displays normal esophageal peristalsis but elevated resting lower esophageal sphincter (LES) pressure and incomplete LES relaxation. The repeat study performed one week later (B) demonstrates normal resting LES pressure and complete LES relaxation. Vascular artefact is present in the distal two esophageal leads. The top tracing represents an integrated recording of submental electromyogram (EMG) (to mark swallows) and respiratory excursions

were markedly agitated during the initial study. When manometry was subsequently repeated with the patients in a calmer state, LES pressure and function had returned to normal.

\section{CASE 1 PRESENTATION}

A 22-year-old Inuit male was referred for investigation of nonstructural dysphagia of two years' duration. The patient spoke no English and therefore a detailed history was difficult to obtain. Barium swallow was suggestive of some incoordination of deglutition but it was unclear from the history whether the dysphagia was esophageal or oropharyngeal in origin. Endoscopic examination was normal with no evidence of hiatus hernia or esophagitis, and therefore esophageal manometry was requested to rule out an esophageal motor disorder. The authors' technique for performing esophageal manometry and provocative testing as well as the manometric criteria for the diagnosis of esophageal motility disorders have been reported in detail previously $(9,10)$. The Dentsleeve manometry catheter (Adelaide, Australia) was passed through the nose and positioned so that all leads initially recorded intragastric pressure. A station pull-through of the LES was then performed and the catheter was positioned so that the sleeve straddled the LES. During the intubation and subsequent recording period the patient appeared to be extremely anxious and agitated. Mean resting LES pressure was elevated at about $40 \mathrm{mmHg}$ above intragastric pressure. Swallow-induced LES relaxation was markedly abnormal, ranging between 30 and $40 \%$ of maximal (Figure 1). Peristalsis in the esophageal body was normal. Neither acid perfusion nor bethanechol provocation produced symptoms or changed the motility patterns.

To evaluate the LES dysfunction further, a repeat manometry was recommended to include balloon distension and cholecystokinin-octapeptide (CCK-OP) provocation (11). This was performed a week later; the patient appeared much calmer and tolerated the intubation well. LES resting pressures were now normal and the swallowinduced LES relaxation was complete (Figure 1). Furthermore, the LES relaxed normally to both midesophageal balloon distension and $40 \mathrm{ng} / \mathrm{kg}$ of intravenous CCK-OP, indicating normal inhibitory innervation to the sphincter.

\section{CASE 2 PRESENTATION}

A 33-year-old Caucasian male was referred for esophageal motility studies for investigation of noncardiac chest pain with concurrent dysphagia. In between pain attacks he was free from dysphagia. Barium $\mathrm{x}$-ray studies and endoscopy were negative. There was no evidence of a hiatus hernia. On the day of the study the patient was remarkably anxious despite repeated reassurances by the physician and the technician. The patient became more agitated and restless after the intubation. The pullthrough LES pressures were normal but, with the sleeve straddling the LES, resting pressures were significantly elevated over $50 \mathrm{mmHg}$ above intragastric pressure. With approximately $40 \%$ of the wet swallows LES relaxation was only $50 \%$ of maximal. All swallows resulted in a normally propagated peristaltic wave, but in one-third of swallows distal contraction amplitude was elevated at more than $200 \mathrm{mmHg}$. Following this, the acid perfusion study was performed which reproduced the patient's chest pain. This was associated with slight disorganization of motility with multipeaked waves. At this point the patient became increasingly agitated and demanded removal of catheter.

He was tried on numerous medications by the referring gastroenterologist, including omeprazole, nifedipine and isosorbide dinitrate, with only temporary symptom relief. He continued to have recurrent episodes of disabling chest pain for many months and the referring gastroenterologist considered performing a pneumatic dilation of the LES. Before proceeding with this, however, a repeat motility study was requested and on this occasion the patient was quite relaxed and calm. The baseline study showed normal resting LES pressure and complete swallow-induced LES relaxation. Esophageal peristalsis was again normal and only one of the 14 wet swallows resulted in a hypertensive contraction in 
the distal esophagus. In view of this finding, pneumatic dilation was not performed. The patient's chest pain resolved following treatment with amitryptyline.

\section{DISCUSSION}

The development of low compliance perfusion manometry systems of high fidelity has brought esophageal motility studies into the modern age. This new technology allowed criteria to be established for normal values based on studies in a large number of healthy adult volunteers $(12,13)$. However, with the improved technology came the appearance of 'new' esophageal disorders. It has been questioned whether these newer abnormal motility patterns represent important disturbances of esophageal function or simply 'curious' manometric findings. Cohen (14) suggested strict criteria to define a manometric finding as an important esophageal disease. Even then there is a significant overlap between normal individuals and subjects with genuine primary esophageal motility disorders. Thus, the observation that experimental stress can induce manometry abnormalities in healthy

ACKNOWLEDGEMENTS: This work was supported in part by Medical Research Council grant \#MA9978. The authors thank Mrs Patricia Perkins, Mrs Sue Owens and Mrs Patti Logan for their technical assistance.

\section{REFERENCES}

1. Young LD, Richter JE, Anderson KO, et al. The effects of psychological and environmental stressors on peristaltic esophageal contractions in healthy volunteers. Psychophysiology 1987;24:132-41.

2. Rubin J, Nagler R, Spiro HM, Pilot ML. Measuring the effect of emotions on esophageal motility. Pyschosom Med 1962;24:170-6.

3. Stacher G, Schmeierer C, Landgraf M. Tertiary esophageal contractions evoked by acoustic stimuli. Gastroenterology 1979;44:49-54.

4. Stacher G, Steinringer H, Blau A, Landgraf M. Acoustically evoked by control subjects should make one cautious in interpreting certain abnormal motility patterns.

Stress-induced esophageal contraction abnormalities have been well documented in the literature as early as 1949 (1-5,7,8), but relatively little has been published concerning stressinduced LES dysfunction. A recent study of healthy volunteers (6) found that artificial stressors resulted in impaired LES relaxation. The authors found coexisting augmentation of diaphragmatic crural activity and suggested that this may be the underlying cause of the impaired relaxation.

The two patients reported above showed marked LES dysfunction during the initial manometry which normalized when the study was repeated. Both patients' resting LES pressure was elevated with evidence of significantly impaired swallow-induced LES relaxation. Although this was consistent with achalasia, the peristalsis in the esophageal body was normal and the barium $\mathrm{x}$-ray was also within normal limits. Both patients displayed marked anxiety and agitation during the first but not the second manometric study, and this is the most likely explanation

esophageal contractions and defense reaction. Psychophysiology 1979;16:234-41.

5. Wolf S, Almy TP. Experimental observations on cardiospasm in man. Gastroenterology 1949;13:401-21.

6. Mittal RK, Stewert WR, Ramahi M, Chen J, Tisdelle D. The effects of psychological stress on the esophagogastric junction pressure and swallow-induced relaxation.

Gastroenterology 1994;106:1477-84.

7. Keshavarzian A, Iber FL, Ferguson Y. Esophageal manometry and radionuclide emptying in chronic alcoholics. Gastroenterology 1987;92:751.

8. Anderson KO, Dalton CB, Bradley LA, Richter JE. Stress: A modulator of esophageal pressure in healthy volunteers and non-cardiac chest pain patients. Dig Dis Sci 1989;34:83.

9. Cole MJ, Paterson WG, Beck IT, DaCosta LR. The effect of acid and bethanechol stimulation in patients with symptomatic hypertensive of the abnormal findings. Whether the abnormal LES relaxation was related to augmented crural activity of the diaphragm or was secondary to true temporary impairment of the inhibitory innervation to the LES is uncertain. Neither patient had evidence of a hiatus hernia; therefore it is conceivable that abnormal contraction of the crural diaphragm was contributing to the manometric abnormality.

\section{CONCLUSIONS}

The above cases suggest that one must consider procedure-related stress as a cause of manometric abnormalities of the LES, particularly when the abnormality does not fit with the overall clinical, radiologic and manometric features. The authors suggest that a repeat manometric study be performed in patients who show significant motility abnormalities but have objective evidence of stress and anxiety during the manometry studies. Alternatively, it may be best to terminate esophageal manometry testing in markedly agitated patients and reattempt the study at a later date. Failure to do so could lead to significant errors in diagnosis and inappropriate therapy.

peristalsis (nutcracker) esophagus.

J Clin Gastroenterol 1986;8:223-9.

10. Paterson WG, Marciano-D'Amore DA, Beck IT, DaCosta LR. Esophageal manometry with provocative testing in patients with noncardiac angina-like chest pain. Can J Gastroenterol 1991;5:51-7.

11. Dodds JW, Dent J. Paradoxical lower esophageal sphincter contraction induced by cholecystokininoctapeptide in patients with achalasia. Gastroenterology 1981;80:327-33.

12. Clouse RE, Staiano A. Contraction abnormalities of the esophageal body in patients referred for manometry. Dig Dis Sci 1983;28:784.

13. Richter JE, Wu WC, Johns DN, et al. Esophageal manometry in 95 healthy adult volunteers. Dig Dis Sci 1987;32:583.

14. Cohen S. Esophageal motility disorders and their response to calcium channel antagonists. The sphinx revisited. Gastroenterology 1987;93:201. 


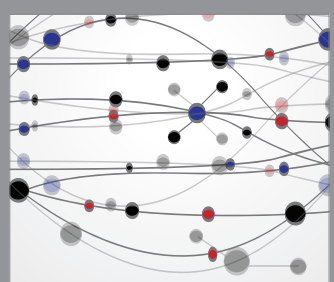

The Scientific World Journal
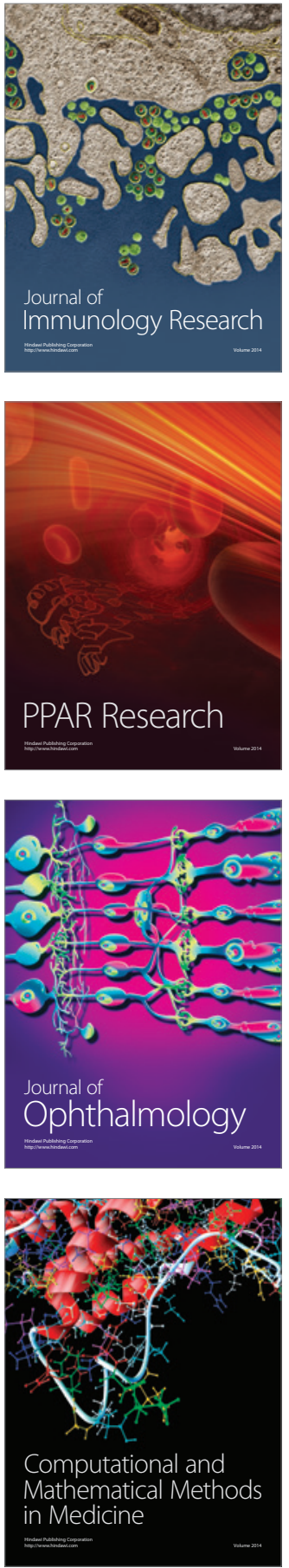

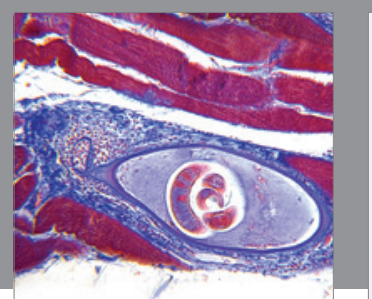

Gastroenterology Research and Practice

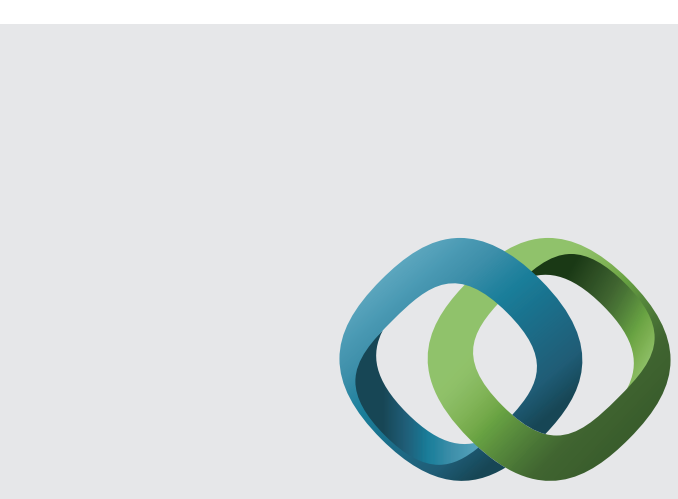

\section{Hindawi}

Submit your manuscripts at

http://www.hindawi.com
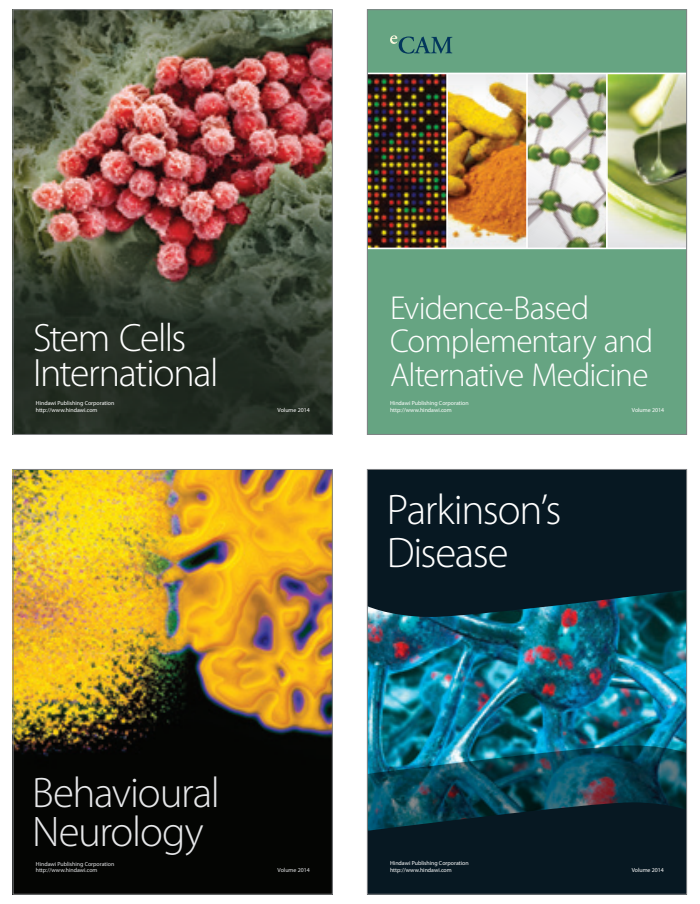
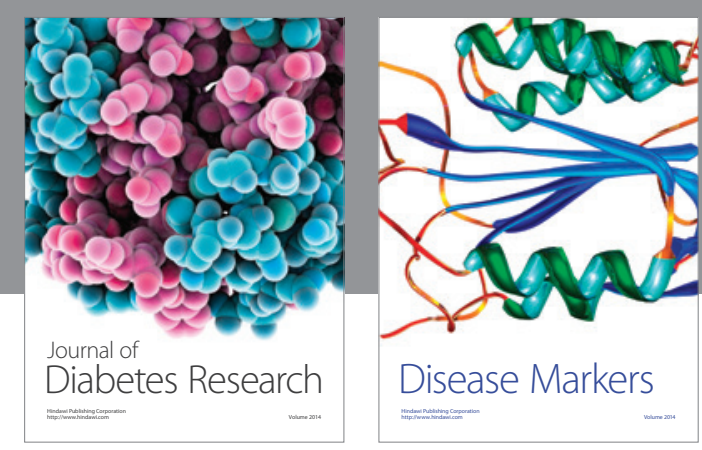

Disease Markers
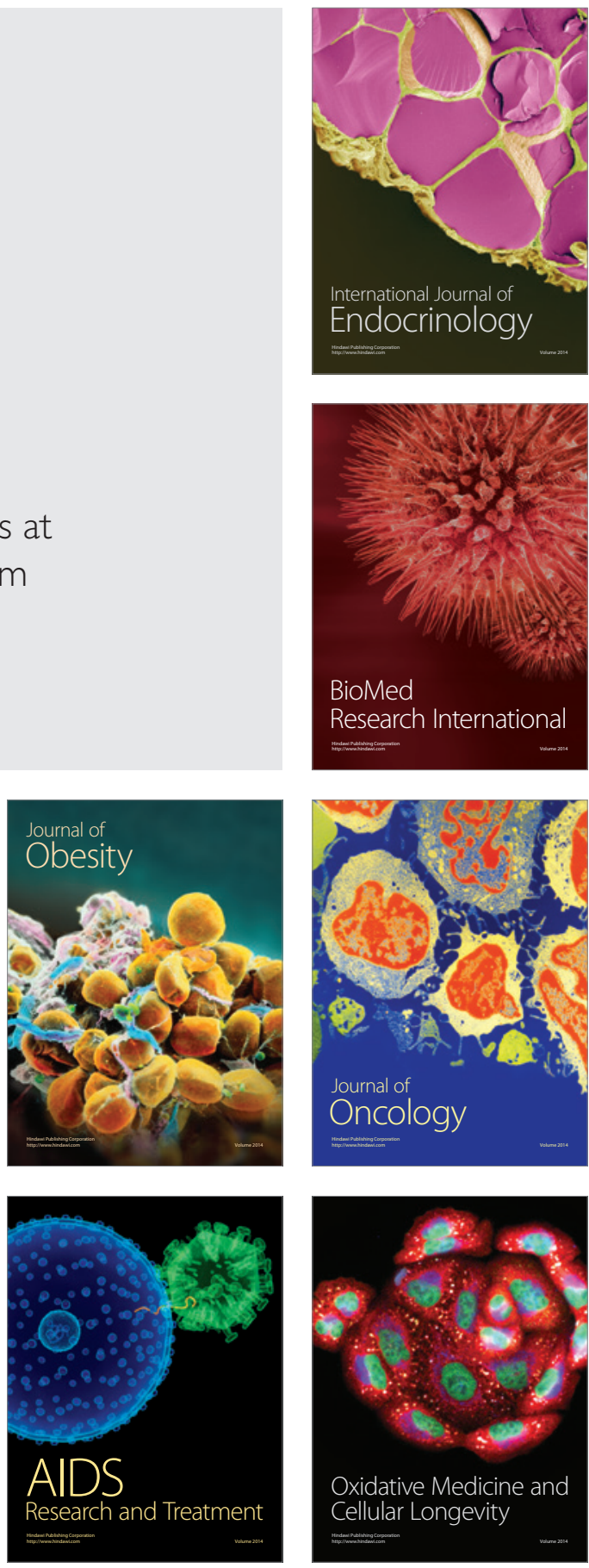